\title{
DJ DOLORES: EXPERIMENTAÇÃO, DIFERENÇA E MEMÓRIA DA MÚSICA ELETRÔNICA
}

\author{
Herom Vargas \& Nilton Faria de Carvalho
}

\begin{abstract}
RESUMO
A trajetória artística do DJ Dolores (codinome de Hélder Aragão) ganhou força durante o movimento manguebeat, na década de 1990, no Recife, capital do estado de Pernambuco, no nordeste do Brasil. Além de trabalhar com produção multimídia, na música sua obra é composta por álbuns experimentais de música eletrônica e também trilhas sonoras para filmes, peças de teatro e espetáculos de dança. Este artigo analisa a diversidade cultural e as misturas organizadas pelo DJ que deslocam as fronteiras dos gêneros musicais hegemônicos articulados pela indústria fonográfica. Ao contrário, Dolores valoriza textos subterrâneos na memória da música pop das mídias, como ritmos de tradições regionais (embolada, coco, maracatu e frevo). A partir dos hibridismos presentes nos álbuns Contraditório? (2002) e Frevotron (2015), respectivamente primeiro e último disco, são identificadas políticas de alteridade e diferença na linguagem, assim como textos culturais e memória, na simbiose entre, de um lado, DJ e tecnologia, e de outro, tradição e instrumentação acústica. No primeiro disco, Dolores toca com a Orchestra Santa Massa, que congrega instrumentos como rabeca, percussões, sopros, guitarra e a voz de Isaar França. No último trabalho, o DJ toca com Maestro Spok, saxofonista de frevo, um percussionista e um guitarrista.
\end{abstract}

\section{Palavras-chave}

D) Dolores; memória; música eletrônica; sampling

\begin{abstract}
D) Dolores' artistic path (codenamed Helder Aragão) arises during the manguebeat movement in the 1990s, in Recife, the capital of Pernambuco state, in northeastern Brazil. In addition to working with multimedia production, in music his work consists of experimental albums of electronic music and also soundtracks for films, theatre play and dance performances. This article analyzes the cultural diversity and mixtures organized by the DJ, which shift the boundaries of hegemonic musical genres articulated by the phonographic industry. Rather, Dolores values underground texts in the memory of media pop music, such as regional traditions rhythms (embolada, coco, maracatu and frevo). As of the hybridisms present on the albums Contraditório? (2002) and Frevotron (2015), respectively first and last discs, otherness and difference policies are identified on the musical language as well as cultural texts and memory, the symbiosis between, on one hand, DJ and technology, and, on the other, tradition and acoustic instrumentation. On the first album, Dolores plays with the Orchestra Santa Massa, which brings together instruments such as rabeca, percussion, wind instruments, electric guitar and the Isaar França's voice. On the last one, the DJ plays with Maestro Spok, frevo saxophonist, one percussionist and a guitarist.
\end{abstract}

\section{KEYWORDS}

DJ Dolores; electronic music; memory; sampling 


\section{INTRODUÇÃo}

A música eletrônica representou mudanças na forma de pensar a criação e a produção musical, e suas primeiras manifestações nas vanguardas do século XX logo escorregaram para o campo da música pop. Começando pelas experiências dos músicos futuristas italianos e passando por John Cage e pela introdução da fita magnética como ferramenta de captação sonora e criação musical, a produção chegou aos computadores e software (Ferreira \& Rabot, 2017). Desde então, disc-jóqueis produtores passaram a experimentar sons sintéticos e organizá-los na elaboração de peças musicais no cenário atual. O aprendizado tradicional, mesmo aquele intuitivo ("de ouvido") baseado no conhecimento de determinadas cadências harmônicas característico da tradição dos músicos populares, deixou de ser o único caminho rumo à composição de canções, após tecnologias oferecerem novas e dinâmicas ferramentas de produção. Também o aprendizado instrumental, fundado no treinamento com instrumentos acústicos ou elétricos, que fora a base para formação do músico popular e que sofrera abalos sucessivos, a exemplo do punk, também deixou de ser atributo obrigatório para ser um músico. $\mathrm{Na}$ música eletrônica, o aparato utilizado pelos DJ - toca-discos, sampler, mixer e software -, que também necessita de aprendizado para saber retirar deles a melhor execução musical, oferece outros modos de pensar e criar música.

Entretanto, é preciso evitar uma atenção direcionada exclusivamente às produções dos DJ para compreender que muitas práticas que caracterizam seus trabalhos podem ser percebidas num vasto histórico das artes em geral. Organizar conteúdos dispersos e questionar determinada erudição acadêmica são traços de muitas correntes artísticas do século XX. Marcel Duchamp ousara adentrar o espaço canônico da tradição renascentista ao reelaborar A Gioconda (Leonardo da Vinci). Sua releitura, todavia, acrescentou um bigode no rosto da famosa imagem de mulher, e ainda aceitou sugestão de seu amigo Francis Picabia e rebatizou-a sob o título de L.H.O.O.Q., cuja leitura em francês, foneticamente, soa algo semelhante à frase "ela tem o rabo quente" ${ }^{1}$ (Ades, 1994). O significado de uma obra escapa ao controle de seu autor na engrenagem da intertextualidade. Três movimentos, neste sentido, são caros ao dadaísmo e também fundamentais na cultura do sampling dos disc-jóqueis produtores: 1) a seleção e organização de textos que produzem e recebem significados na cultura; 2) o questionamento à obrigatoriedade de uma formação erudita para fazer arte; e 3) o uso de materiais não tradicionais para elaboração da obra de arte.

O músico que destacamos neste artigo, DJ Dolores (codinome de Helder Aragão), é nascido em Propriá, no estado de Sergipe, nordeste brasileiro. Com o pai músico, conheceu várias tradições e movimentos musicais, tanto locais quanto nacionais e estrangeiros, como choro, MPB, jazz, rock e o tropicalismo. Na adolescência, com a mudança da família para Aracaju, capital do estado, foi baterista de um grupo de punk rock. Em 1984, chegou a Recife, capital de Pernambuco, e conheceu Fred 04, Renato Lins, Chico Science, entre outros, grupo de jovens que viria a formar o núcleo central do

\footnotetext{
"Elle a chaud au cul".
} 
manguebeat, um movimento musical e cultural centrado na cidade e que chacoalharia a música brasileira na década de 1990.

O fato de ter tocado bateria na adolescência, se não o tornou um exímio baterista, proporcionou uma sensibilidade intuitiva para os ritmos, como demonstram seus trabalhos em composição de trilhas sonoras e sua obra como DJ e produtor de música eletrônica. É claro seu interesse em ritmos regionais nordestinos, na presença constante de um percussionista em gravações e apresentações ao vivo e na sua forma de tocar, samplear e mixar batidas eletrônicas. No primeiro disco do DJ Dolores, o álbum Contraditório? (2002), o disc-jóquei manipula software ${ }^{2}$ ao lado da Orchestra Santa Massa, grupo que o acompanhava e que trazia, na sua forma de tocar, diversos elementos instrumentais e rítmicos tradicionais de regiões pernambucanas e referências sonoras em diáspora: a voz e a percussão de Isaar França (ex-membro do grupo Comadre Florzinha), a rabeca de Maciel Salú, a percussão de Jam da Silva, a guitarra de Fabio Trummer (integrante do grupo Eddie), entre outros músicos nos metais e percussão que esporadicamente compõem a formação instrumental. Uma banda e um DJ, sons elétricos, acústicos e digitalizados, locais e globalizados. Esse traço hibridizado perdura nas obras do artista, em especial na mais recente, o projeto Frevotron (2015), na qual o ritmo estilizado do frevo e as melodias do saxofonista Spok encontram outras sonoridades sintéticas, percussões e os riffs de guitarra de Yuri Queiroga.

As obras do DJ Dolores transitam livremente entre tradições populares do nordeste brasileiro, música eletrônica e gêneros como o rock e o hip hop, diversidade essa que compõe um dos aspectos estéticos do movimento manguebeat, ao qual o artista está umbilicalmente vinculado. O senso rítmico, construído na fase em que fora baterista e apurado ao longo da carreira, marca uma das características de suas composições. Canções de linguagem híbrida - tal qual as que surgiram com o manguebeat de grupos como Chico Science \& Nação Zumbi -, conforme os conceitos da Semiótica da Cultura, organizam em sua estruturalidade textos de diferentes vertentes culturais. E essa dinâmica que tende à mistura, na música ou qualquer outra linguagem artística, é típica de textos situados nas fronteiras entre sistemas culturais distintos, regiões de tradução e de intensa movimentação de sentido, pois reúnem textos tanto componentes de memórias, sedimentadas em níveis distintos e acionadas ao sabor do interesse do músico ou da dinâmica cultural em questão (Lotman, 1998), quanto textos outros de origens diversas que representam configurações em constante atualização.

O objetivo deste artigo é demonstrar que o perfil experimental do DJ Dolores, ao colocar culturas populares e referências da música eletrônica e de outros estilos musicais em contato no perfil híbrido de suas obras, desloca regimes semânticos da indústria fonográfica por não se encaixar nos limites dos gêneros musicais estabelecidos pelo mercado produtor e consumidor.

Como metodologia, a análise das canções usa conceitos da Semiótica da Cultura para compreensão da linguagem musical. O objetivo é identificar elementos sônicos

\footnotetext{
2 Em entrevista ao canal Batebit Artesania Digital, o DJ Dolores afirmou que usa os programas Pro Tools e Ableton Live para elaborar suas produções e também durante as apresentações ao vivo. Retirado de https://www.youtube.com/ watch? $=\mathrm{E}_{2} \mathrm{~W}_{7} \mathrm{ZdnU}_{3} \mathrm{H}_{4}$.
} 
que diferenciam tais obras, pensadas como textos culturais, de produções hegemônicas na música pop, trazendo também contribuições teóricas dos estudos de memória e dos Estudos Culturais, uma vez que essas músicas experimentais articulam novas formas de representação nas mídias.

Sobre hibridismos na linguagem, entendemos tais configurações como não aderentes a taxonomias que, de maneira geral, fazem parte da gestão da vida social: Por incorporar o dialogismo e ser polifônico por excelência, o hibridismo é um processo selvagem de rompimento com as estabilidades teóricas e com as esperanças de unicidades semânticas; mas, ao mesmo tempo, mostra-se docemente criativo por trazer em si, potencialmente, os germes de novas alternativas para as mais assustadoras combinações. (Vargas, 2007, p. 23)

\section{MEMÓRIA, GÊNERO E REGIME SEMÂNTICO}

Outra visão acerca da memória, um pouco além do seu entendimento na Semiótica da Cultura, é a reconstrução, percebida nas obras do DJ Dolores, de narrativas sonoras historicamente silenciadas no ambiente midiático. É preciso, antes, não perder de vista que na oferta de estilos musicais enquadrados no limite dos gêneros fonográficos há valorização de certos textos hegemônicos ao contrário de outros. Mesmo que na circulação e consumo de produtos midiáticos os significados possam tomar múltiplos trajetos, muito além da noção de ideologia implacável das indústrias culturais, a cultura da mídia é constituída por relações assimétricas de poder. De forma geral, quando determinado rótulo musical é fixado e oferecido ao consumo - hoje não necessariamente associado à compra física ou virtual, mas mensurado a partir de cliques e acessos a plataformas de streaming -, nota-se um comportamento harmonizado de reconhecimento por parte dos ouvintes. A memória midiática, neste caso, é um campo narrativo e semiótico no qual alguns textos são amplamente lembrados, decodificados, traduzidos e reatualizados em detrimento de outros, que poucas vezes são citados e, consequentemente, experimentados. As constantes lembranças e repetições conduzem, na maioria dos casos, a reconhecimentos mais imediatos, construções identitárias já conhecidas e respostas mais positivas e afetivas no consumo musical. Às vezes, como a cultura é dinâmica e móvel, algum dado novo interfere nessa produção e altera a recepção com certo estranhamento, logo incorporado e traduzido a um novo consumo.

No caso do trabalho do DJ Dolores, o processo de estranhamento é maior. $\mathrm{Na}$ linguagem intertextual dos dois álbuns analisados neste artigo, a reorganização intercultural conduzida pelo artista abre várias e inusitadas possibilidades de encontros, diferente da dinâmica mais definida dos gêneros fonográficos que, quanto mais fechados em sua estrutura semântica e formal, mais conectados estão com as regras enunciativas dos estilos hegemônicos aos quais estão associados historicamente. Por esse motivo, o uso de samples em misturas sonoras que ressaltam também sons locais representam 
movimento semelhante ao trabalho de um arqueólogo, no sentido benjaminiano, capaz de questionar grandes narrativas, pois coloca em evidência subjetividades subterrâneas e articula conceitos outros de história (Benjamin, 1987; Pollak, 1989).

Em princípio e de forma geral, gênero musical na música popular é uma forma de estruturação da canção reconhecida e partilhada socialmente pelos artistas e pelo público e se fundamenta em processos de produção de sentido com aceitação coletiva. Podemos pensar os gêneros, a partir de Franco Fabbri (1982), como conjuntos de elementos musicais (ritmo, melodia, formação instrumental, etc.) aceitos social e culturalmente em determinadas comunidades de produtores e ouvintes. Tais elementos também se estruturam em níveis externos à música, mas sempre em relação a ela: dança, comportamento, modos de fala, ideologia, etc. São convenções enunciativas acionadas dentro da comunidade de produtores e consumidores cujos significados são reconhecidos e partilhados em determinado circuito. Se modularmos essa ideia para o contexto da indústria fonográfica e do consumo musical, é como se determinadas formas se fixassem para, a partir do reconhecimento e de respostas afetivas, servir à circulação da canção enquanto mercadoria: quanto mais definida, maior será, em princípio, a tendência ao compartilhamento dessa forma.

Obviamente, seguindo a noção dinâmica de cultura que está na base da Semiótica da Cultura, esse sistema sempre se transforma com os contágios externos, traduções ou criações internas, porém, sempre dentro desse "contrato" de produção e reconhecimento dentro da comunidade de criadores e ouvintes.

Mesmo que esse complexo conjunto de elementos dinâmicos seja bastante móvel e determinante, para Felipe Trotta (2008, p. 2), há "certa primazia dos parâmetros sonoros (regras técnico-formais) sobre os demais como condição prévia para estabelecimento para outras regras de gênero". E desses parâmetros sonoros, dois parecem ser preponderantes: o ritmo e a sonoridade. O ritmo é o dado básico de cadência e velocidade que define grande parte do sentido atribuído a uma peça musical popular, aquele que afeta o corpo, que o mobiliza e o faz entrar em sintonia com a música. É o movimento para a dança que, por sua vez, se constrói na audição compartilhada e no contexto coletivo da festa. Já a sonoridade é "o resultado acústico dos timbres de uma determinada performance, seja ela em gravações (sonoras ou audiovisuais) ou executada 'ao vivo'" (Trotta, 2008, p. 3). Aqui, nos referimos às sonoridades de instrumentos e vozes, a como soam os instrumentos em função das execuções. Ou seja, cada gênero guarda alguma relação central com determinadas formações instrumentais, timbres e jeitos de cantar e maneiras de fazer tudo isso soar. No rock, não basta ter uma guitarra, mas ela deve soar de algum jeito específico para ter certo sentido e poder ser reconhecida dentro da música (Baugh, 1994). Da mesma forma, não basta haver um tamborim para se ter um samba, mas ele deve ser tocado com certa particularidade para que seu som seja partiIhado pelo público em uma peça musical reconhecida como samba. Quando se fala em música sertaneja, pede-se que o cantor use a voz seguindo determinados parâmetros e que a prosódia também seja específica. 
Há duas situações possíveis nos processos de mudança em que se destaca a diferença. Assim como os elementos sonoros constitutivos dos gêneros - seus estilemas - constroem processos identitários na cultura, qualquer alteração na execução desses parâmetros, seja com exagero, inversão ou mescla com outros códigos musicais, pode ter como consequência a mudança no regime semântico e um possível rompimento no processo de identificação por parte do ouvinte. Ou seja, numa situação extrema, a canção será negada pela comunidade, pois não se enquadra mais nos parâmetros do gênero musical definidos anteriormente. De outro lado, tal alteração poderá ser aceita e incluída pela comunidade como parte de uma nova configuração do gênero. Neste caso, o processo identitário se amplia e se reforça em novos patamares de sentido.

A rigor, as ações de reconhecimento/aproximação, de um lado, e as de negação/ afastamento, de outro, são apenas dois extremos de uma relação complexa, móvel e com múltiplos resultados. Canções e gêneros na música popular nas mídias são estruturas semióticas nômades, ou seja, sofrem mais trânsitos estilísticos e de consumo do que suas definições conceituais conseguem circunscrever. Essas transformações podem ser, inclusive, motivo de criação e inovação dentro do gênero, com prejuízos ou sucessos no consumo das novidades.

No caso dos gêneros musicais trabalhados pela indústria fonográfica, há uma tendência a privilegiar os vetores de reconhecimento e aproximação. Consequentemente, reiteram-se regimes semânticos em que os estilemas dos gêneros são mais estáveis e definidos, mesmo que com certo grau de transformação e adaptação.

Retomando o trabalho do DJ Dolores, no álbum Contraditório? (2002), sua parceria com a Orchestra Santa Massa3, composta por uma combinação instrumental de voz, guitarra, baixo, bateria, rabeca e sopros, representa as mesclas culturais de sua linguagem musical. As presenças e performances do grupo, os timbres de vozes, da rabeca e das percussões que compõem a paisagem sonora acionam lembranças de emboladas, cocos e maracatus. Mas, ao lado dos sons da guitarra e dos samples, acionam também novas e distintas percepções, constroem novas gramáticas para leituras inovadoras do som que emana justamente de cada especificidade material e de sua execução. A preocupação com a disposição presencial e instrumental da junção DJ e banda joga luz sobre a importância das materialidades no processo comunicacional, o que "significa ter em mente que todo ato de comunicação exige a presença de um suporte material para efetivar-se" (Felinto, 2001, p. 3). No álbum homônimo do projeto Frevotron, de 2015, DJ Dolores, Maestro Spok e Yuri Queiroga partem da matriz semântica "frevo" para explorar outros campos sonoros, com instrumentação que reúne saxofone, guitarra, baixo, sintetizadores e software, somados às participações especiais de Otto, Jorge Du Peixe (Nação Zumbi), Marion Lemonnier, Sombra, Lira e Jam da Silva. Corpos, instrumentos e recursos tecnológicos de produção são materialidades que afetam percepções, pois participam do processo comunicacional de transmissão do som, cada qual em sua singularidade, seja o vibrar de cordas transformado em ondas elétricas ou a reprodução de sons digitalizados. O artista convidado traz consigo um ethos. Em outras palavras,

${ }_{3}$ Sobre a banda, ver http://orchestrasantamassa.tnb.art.br/ 
performance, voz e presença física são fatores enunciativos que inscrevem sentidos e subjetividades na linguagem.

Contraditório? (2002) e Frevotron (2015) serão entendidos a partir da complexidade de suas configurações híbridas, aspecto que demanda combinações teórico-metodológicas. Optamos por compreender a linguagem por meio da Semiótica da Cultura e das políticas de identidade com contribuições dos Estudos Culturais - por entender que "o ser social [é composto por] laços múltiplos que, por sua vez, enlaçam outras redes de relações num processo potencialmente infindável" (Ribeiro, 2010, p. 199) -, mas sem perder de vista as materialidades comunicacionais que envolvem obras e artistas, capazes de tangenciar percepções. Por fim, essas obras levadas ao ambiente midiático, por produzirem diferença, serão compreendidas como rompimentos em relação aos quadros hegemônicos na memória da música pop, delimitações estéticas inerentes à gestão da vida social. Mas antes de adentrar tal análise, é preciso ressaltar alguns pontos acerca do uso da tecnologia na produção musical contemporânea que, a princípio, pode representar perda de referência característica de crises pós-modernas, e ao mesmo tempo assumir o papel de resposta subjetiva frente a uma visão negativa sobre o uso de aparatos tecnológicos.

\section{DJ E TECNOLOGIAS: PÓS-MODERNO OU SIMBIOSE SOCIOTÉCNICA?}

No campo da música pop, foram os primeiros experimentos do grupo alemão Kraftwerk na década de $1970^{4}$ que influenciaram o surgimento da música eletrônica, inspirados, sobretudo, por vanguardas como o suprematismo e movimentos artísticos como a Bauhaus. Não à toa, capas de discos lançados pelo grupo fazem menções a obras do russo Kazimir Malevich (1878-1935), por exemplo, artista que rompeu com a arte figurativa. O experimento, no caso do Kraftwerk, ocorreu com o uso de sons eletrônicos, efeitos geradores de vozes com timbres robóticos, colocando no cenário pop preocupações humanas a respeito do uso das tecnologias. No cinema, a abordagem do porvir tecnológico também fez parte de inúmeros filmes e a proximidade entre corpo humano e máquina, seja na figura do ciborgue Darth Vader (Star wars) ou na caça aos androides em Blade runner, revelou por vezes temores e incertezas.

Em outro lugar, nas periferias de Kingston, ao final da década de 1960, experimentalismos marcavam também o uso de tecnologias nos estúdios jamaicanos, notadamente por nomes como Lee "Scratch" Perry, King Tubby e Ruddy Redwood, entre outros. Diferente de leituras negativas, no caso dos produtores jamaicanos o uso de aparelhagens ganhou contornos de resistência, quando, concomitante ao surgimento do rocksteady (que antecede o reggae e o dub), permitiu aos artistas locais a possibilidade de gravar seus próprios discos e consolidar assim ritmos originários da Jamaica5. Da mesma

\footnotetext{
4 Uma das primeiras apresentações do grupo Kraftwerk ocorreu na cidade de Soest, na região oeste da Alemanha. O registro mostra a preocupação da banda em explorar sons até então pouco habituais na cultura pop. Retirado de https://www. youtube.com/watch?v=YF1B4smQL7s

${ }_{5} \mathrm{O}$ documentário $\mathrm{A}$ história da música jamaicana aborda os ritmos nascidos na Jamaica. Retirado de https://www.youtube. com/watch?v=OJyszsYQmLs
} 
forma que os jamaicanos ressignificaram o rhythm and blues (R\&B) na elaboração do ska, décadas depois, devolveram ao chamado Primeiro Mundo o reggae, que exerceu forte influência no hip hop dos EUA e no drum'n'bass britânico. Ao assumir o controle de aparelhos, os jamaicanos produziram mudanças inclusive no âmbito das economias políticas de circulação e consumo de canções, num sentido descolonizante.

A chegada de simuladores digitais que reproduzem timbres de uma série de instrumentos, assim como as interfaces MIDI (Musical Instrument Digital Interface), controle simples de múltiplas fontes instrumentais, representaram outras mudanças nos modos de criação. Tais ferramentas oferecem alternativas à produção de discos em estúdios, já que o artista pode gravar e editar sua obra no quarto de sua casa. Entretanto, a limitação dos dados armazenados nos software pode significar a engrenagem de um tipo de manutenção semântica da canção a ser produzida, e sua (re)produção pode gerar a repetição de conteúdos já conhecidos. Não se pode ignorar que controle, poder e consumo jogam por terra qualquer discurso que aponte neutralidade na tecnologia, basta ter um apareIho de celular obsoleto, cujo sistema e aplicativos vão gradativamente deixando de ter atualizações, para perceber as coerções aplicadas por esses dispositivos. Assim, como um desdobramento do biopoder, novas técnicas de gerir subjetividades são aplicadas na virtualidade da era digital, em um mundo de muitas telas.

No momento em que o potencial revolucionário da tecnologia é reduzido ao estado de dispersão e perda de referência, sobretudo a partir de um olhar com base na teoria pós-moderna, tem-se a sensação de instalação de crise no mundo contemporâneo. Ao refletir sobre um cenário cada vez mais tecnológico, permeado por máquinas e pela ciência, Jean Baudrillard (1991) escreve o seguinte:

os atuais seres tecnológicos, as máquinas, os clones, as próteses, tendem em sua totalidade para esse tipo de reprodução e induzem lentamente o mesmo processo nos seres humanos e sexuados. Todas as tentativas atuais, entre elas a pesquisa biológica de vanguarda, tendem para a elaboração desta substituição genética, de reprodução sequencial linear, de clonagem, de partenogênese, de pequenas máquinas solteiras. (Baudrillard, 1991, p. 13)

A perda de referência e também o esgotamento da produção de sentido - repetições cumprem bem esse papel - são sintomas de um efeito homogeneizante que ganhou força com a globalização e a comunicação digital. No caso da música, a repetição de certas fórmulas estéticas fixou na cultura midiática muito mais do que meros gêneros, mas socioestilos e comportamentos, colocando semelhanças dentro de um campo semântico e, por fora, tudo o que possa estar relacionado com significados de diferença, estranheza e novas experiências.

Essa dialética entre dentro e fora é mais dinâmica do que se imagina e não significa serem mundos estanques e separados. As interpenetrações são, em grande número, tendo em vista a forte capacidade de incorporação das indústrias culturais, a do reconhecimento e da repetição. $O$ conceito de música eletrônica vinculado em grandes festivais, como o Tomorrowland, por exemplo, valoriza disc-jóqueis que figuram em cenários 
mainstream e geralmente estão associados a um tipo previsível de construção, dentro das expectativas de um público acostumado ao "som das pistas". Os beats sintéticos que embalam hits modernos podem variar pouco dentro do tempo de duração do evento, pois outros aspectos simbólicos (bebida, substâncias alucinógenas e público jovem) complementam a "experiência" oferecida no pacote da festa. Em outras palavras, não é o simples fato de deslocar formas antigas de composição (que faz uso de instrumentos tradicionais) que coloca a música eletrônica como rompimento semântico contemporâneo. Muito pelo contrário, na maioria das vezes, trata-se de um produto midiático que atende aos moldes de uma engrenagem mercadológica hegemônica. Nesses casos, o estilo musical cai no esgotamento de sentido característico de textos culturais pós-modernos, "cujos significados comunicam simplesmente a si mesmos, nada mais" (Kellner, 2001, p. 371), bastando soar dançante, entreter e ser uma das atrações do evento.

O trabalho do DJ Dolores, no entanto, não se limita a operar dentro dos limites dos software e bancos de dados (samples) de sons digitalizados e festas rave. Ao lado de variações nas formações instrumentais que o acompanham, o artista explora outros ritmos e o rótulo "música eletrônica" seria incapaz de dar conta da complexidade e da diversidade do seu trabalho. O experimentalismo do artista provoca um afastamento dos módulos socioestéticos, ao ponto de sua obra, caso fosse apresentada a determinado público acostumado às baladas de música eletrônica, soar como algo estranho, desajustado aos padrões geradores de conforto. Assim, aquele "contrato" que citamos anteriormente entre parâmetros musicais e o reconhecimento da comunidade no que se refere a gênero, no caso do DJ Dolores, é rompido e ele pode deixar de ser aceito e definido como "música eletrônica" por determinado público ligado ao mainstream. Não é possível afirmar que, conforme Kellner (2001), há algum esgotamento. Ao contrário, Dolores trabalha com os signos da abertura, da experimentação e da novidade. Por esse motivo, sua obra não pode ser compreendida à luz do conceito de pós-modernidade.

A simbiose entre DJ, tecnologia e instrumentação remete à ideia de pós-humano, mas difere de configurações despolitizadas que integram os discursos de neutralidade da tecnologia e do progresso na atualidade. Trata-se de um agenciamento sociotécnico que produz diferença na música pop. Por meio de hibridismos na linguagem, os discos Contraditório? e Frevotron colocam em circulação textos culturais historicamente ignorados nos ambientes midiáticos mais conhecidos. Frevos e emboladas, presentes nos trabaIhos do disc-jóquei, são mencionados nas grandes narrativas midiatizadas como elementos de um folclore nacional, algo obsoleto em comparação ao imediatismo jovem do pop.

Donna Haraway (2000), ao enfrentar em seu Manifesto ciborgue o porvir tecnológico, preferiu estabelecer uma discussão teórica diferente da elaborada por Baudrillard. Para a autora, existe uma potência emancipadora no pós-humano, temática sempre instigante nas literaturas acadêmica e ficcional, na qual a simbiose humano-máquina subverteria, entre outros quadros ocidentais, as possibilidades de gênero, multiplicando os sexos e superando o binarismo masculino/feminino. Sobre o ciborgue, a autora escreve o seguinte: 
um ciborgue é um organismo cibernético, um híbrido de máquina e organismo, uma criatura de realidade social e também uma criatura de ficção. Realidade social significa relações sociais vividas, significa nossa construção política mais importante, significa uma ficção capaz de mudar o mundo. (Haraway, 2000, p. 36)

Sua resposta para a tecnologia idealizada sob a lógica positivista, de um progresso que atropela subjetividades para reforçar limitações textuais e linearidades comunicacionais estáveis, é a produção de uma linguagem dialética, política e de posicionamentos identitários plurais. Como a faixa Diáspora, do álbum Frevotron, que coloca o pós-humano em situação para além dos limites semânticos de um gênero específico, com efeitos de delay semelhantes aos do dub jamaicano, frases de guitarra (Yuri Queiroga), sopro (Spok) e trechos cantados por Dolores, que citam "Congo, Angola". Caixas de percussão e sintetizadores, significados transnacionais de signos musicais em diáspora.

\section{HIBRIDISMOS, COMUNICAÇÃO E DIFERENÇA NA MEMÓRIA DA MÚSICA POP}

A mescla dos elementos estético-culturais que compõem os discos Contraditório? e Frevotron remete à diversidade das metrópoles contemporâneas e ganha velocidade comunicacional na virtualidade do mundo em redes, produzindo diferença no ambiente midiático. Tecnologias, ritmos, culturas, gêneros e artistas se conectam na geração de linguagem.

No álbum Contraditório?, a instrumentação acústica da Orchestra Santa Massa ${ }^{6}$, composta por músicos conhecedores das vertentes musicais recifenses, é trabalhada em sintonia com software manipulado pelo DJ Dolores. O encontro do DJ com o grupo, nesse caso, resulta efeito polifônico e ritmos tradicionais ocupam o mesmo espaço das frequências do sintetizador e dos samples, dentro de uma complexidade de materialidades portadoras de sentidos. Tais presenças são fundamentais para o entendimento da linguagem híbrida que se constrói, tanto no fonograma acabado como na imprevisibilidade da performance ao vivo.

A faixa Que som é esse? ${ }^{7}$ soa provocante, em seu nome interrogativo, ao convidar o ouvinte a desvendar seus elementos sonoros. Software permite inserção de samples, frases ditas em versos soltos - como a expressão "afina a guitarra" - como se resgatasse conversas do ambiente de gravação para uma atualização do passado, ou seja, um sampleamento nunca é repetição, mas produção de diferença e ressignificação, outro devir, um fragmento aparentemente deslocado que produz sentido pelo conceito cultural ou de origem que encerra em si próprio ou pela fricção semântica que provoca no discurso em que se insere. Segundo Conter e Silveira,

\footnotetext{
${ }^{6} \mathrm{~A}$ banda é composta, nesse disco, por Isaar França (vocalista e percussionista), Fábio Trummer (guitarrista e vocalista), Jam (percussão), Maciel Salu (rabeca), Deco (trombone), Parro (sax) e Yuri Queiroga (baixo).

7 Retirado de https://www.youtube.com/watch?v=xFfiWej8nKs
} 
o sample é como uma citação bibliográfica sem referência (a não ser que o ouvinte a reconheça de imediato). Não é uma crítica ao zeitgeist, mas uma atualização do passado. Um processo de diferenciação. (...) Cada sample (...) não é como um texto escrito, um discurso, mas um conceito. Se o nome próprio não pertence à linguagem, o sample também não pertence à linguagem musical, já que não pode ser transcrito numa partitura. (2014, p. 56)

A canção ainda usa o triângulo do baião no contexto da pulsação do beat eletrônico, num campo sonoro em que a única conexão é a da convivência rítmica. Não à toa, o Recife do DJ Dolores e da Orchestra Santa Massa é o das liberdades criativas de horizontes complexos do manguebeat, lugar e tempo em que surgiram grupos como Chico Science \& Nação Zumbi, Mundo Livre S/A, Mestre Ambrósio, Comadre Florzinha, entre outros. Nas metrópoles, todas delas, há aproximações entre tradições e textos culturais globalizados. O manguebeat é exemplo de tal contato, sobretudo por sua constituição a partir de instrumentação pernambucana e gêneros musicais afro-americanos globais, e as identidades emergentes desses contextos estão em constante relação de alteridade (Hall, 2003, p. 74; Vargas, 2007, p. 17).

O fato de lidar com sons digitais, no lugar de ter passado por aprendizado em conservatórios musicais, coloca também o DJ em constante relação com as mudanças culturais da era pós-industrial. A quebra de limites do pós-humano, a simbiose DJ-máquina, produz na linguagem musical a simulação de práticas inerentes à cultura remix, fenômeno pautado na constante reelaboração de informações. No álbum Contraditório?, por exemplo, Dolores assina duas versões da canção Catimbó, sendo que na segunda acrescenta ao título o termo remix, como indicativo de reedição que ganhou novos arranjos. Apesar de ser amplamente praticado, como os remakes do cinema ou compartilhamento de conteúdos variados nas redes (memes, mash ups, gifs, etc.), é preciso ampliar a compreensão do tempo histórico e pontuar que esse tipo de produção intertextual era recorrente nas artes visuais, em especial na vanguarda dadaísta e posteriormente na arte pop. E no caso da música, a lógica de versões como Catimbó remix possuiu relação com as experiências dos produtores jamaicanos idealizadores do dub. King Tubby, Lee "Scratch" Perry e Augustus Pablo, com poucos recursos tecnológicos, começaram a reaproveitar materiais descartados em sessões de gravação (sucata sonora) e os discos gravados na Jamaica geralmente eram lançados com repetições de faixas. A segunda se tratava da "versão dub", que tinha em sua estrutura a valorização dos sons do baixo e bateria ${ }^{8}$, além outros efeitos como ecos e overdubs (sons adicionais variados). Assim, na remixagem de Catimbó 9 , percussão e batidas eletrônicas são mantidas e ganham destaque, há momentos de delays (ecos) e a voz da cantora Isaar França é omitida, permanecendo apenas uma voz robótica que pronuncia a palavra "catimbó". As várias camadas de timbres instrumentais apontam para as relações de textos distintos construídas pelo

\footnotetext{
${ }^{8}$ Quando as versões eram marcadas principalmente por esse destaque conferido ao baixo e à bateria, as faixas também eram chamadas de riddims.

${ }_{9}$ Retirado de https://www.youtube.com/watch?v=a86BKp4IAmg
} 
arranjo. Se o título da canção se refere a rituais religiosos indígenas, a tessitura de sons busca reconstruir um ambiente sonoro mântrico com instrumentos de origens distintas, no tempo e no espaço: a voz de cantora negra de Isaar que remete aos cantadores tradicionais do sertão, o xequerê de toque ritmado em sintonia com seu corpo, a rabeca ancestral de Maciel Salu, o percussionista fazendo soar com duas vassourinhas um derbake de origem árabe, a guitarra mais rítmica e com pequenas e pontuais melodias, tudo isso circulando os samples de Dolores. O arranjo instrumental mapeia tempos e espaços distantes e hibridiza suas sonoridades em camadas porosas, como numa zona de fronteira em que sons de sistemas externos penetram e são traduzidos em novas sintaxes nas relações com elementos das músicas regionais. O que se percebe é que Catimbó soa eletrônico, sertanejo, roqueiro e árabe num só texto acústico e rítmico, um texto forjado na multiplicidade cultural.

Na proposta arqueológica de Sigfried Zielinski (2005, p. 56), há a sugestão teórica e metodológica de "desenterrar caminhos secretos na história, o que poderia nos ajudar a encontrar nosso caminho para o futuro". A recorrência dessa prática de remixagem, seguindo uma visão arqueológica, nos ajuda a compreender que essas reedições não são exclusividade da contemporaneidade, mas demonstram as preocupações que a arte desenvolve de tempos em tempos, no momento em o artista que deseja modificar algo na obra acabada, alterando alguns elementos na montagem de uma nova versão. Assim, mesmo que percebamos a recorrência de reedições na contemporaneidade (Reynolds, 2011), e a web contribui com esse fenômeno, seria equivocado considerá-lo como algo atribuído ao presente, sem ampliar o olhar para o entendimento de um tempo histórico estendido e em constante relação (passado, presente e futuro).

O álbum Frevotron, capítulo mais recente na obra do DJ Dolores, é marcado pela parceria com os músicos Maestro Spok (saxofones) e Yuri Queiroga (guitarra, baixo e sintetizador). O trabalho abre com a faixa Invocação $\# 2^{10}$, com sax e percussão (caixa), elementos característicos do frevo tradicional executado em Pernambuco, mas que soam na mesma paisagem sonora dos efeitos simulados ao sintetizador. A participação do músico Queiroga soma à linguagem acordes de guitarra que, em determinado momento, alteram a cadência rítmica do frevo para algo mais próximo à do reggae, enquanto sons sintéticos preenchem o espaço acústico com efeitos de delay. À luz da Semiótica da Cultura e o conceito de semiosfera que estabelece a existência de espaços comunicacionais onde ocorre a semiose (produção de sentido), a canção Invocação \#2, da mesma forma que Catimbó, tem sua codificação emergente de pontos em que diferentes semiosferas se tocam. Em outras palavras, sua linguagem surge de regiões fronteiriças entre as semiosferas do frevo, do reggae e da música eletrônica. O que Dolores, Spok e Queiroga fazem ao reunirem esses textos culturais (os elementos sonoros característicos desses campos rítmicos), até então dispersos, é modelizá-los na configuração híbrida do disco Frevotron.

Por esse motivo a experiência semiótica oferecida pelos álbuns Frevotron e Contraditório? produz diferença no ambiente midiático. Suas composições, estruturadas em

\footnotetext{
${ }^{10}$ Retirado de https://www.youtube.com/watch?v=dNFhY3tUOUk
} 
complexas materialidades acústicas, diferem antes do "efeito constituído como diferente", como escreveu Jacques Derrida (1991, p. 39) acerca do constante deslize do termo différance. A disposição física do sampler, da guitarra, das percussões e dos sintetizadores não se encaixa na decodificação determinada pelas narrativas hegemônicas da música pop. Quando DJ Dolores encontra a Orquestra Santa Massa, no disco Contraditório?, ou Spok e Queiroga, no projeto Frevotron, a linguagem musical tende a se deslocar e entrar em intenso contato com as fronteiras das semiosferas. Nessas regiões periféricas, afastadas do contexto nuclear do pop, outros textos emergem (frevo, maracatu, dub, reggae, carimbó). Embora esses textos sejam produtores de diferença na memória midiática da música pop, a rearticulação da memória, nos escritos de luri Lotman (1998), é substância sígnica inerente às linguagens complexas. Para o autor, "quanto mais complexa é uma linguagem, quanto mais ajustada está para a transmissão e produção de informação mais complexa, maior profundidade deve possuir sua memória" (Lotman, 1998, p. 155).

Em outro ângulo de compreensão da memória está o ato de construir uma narrativa que valoriza algumas representações em detrimento de outras. A memória seria essa constante rearticulação dialética de lembrança e esquecimento. Na canção Samba de dez linhas" ${ }^{11}$, do disco Contraditório?, a linguagem de beats acelerados sofre uma quebra rítmica que abre caminho para a voz de um cancioneiro. A mudança propõe o deslocamento de um território sonoro ambientado na música eletrônica para outra territorialidade: o sample que simula o cantor nordestino, os acordes de sanfona, o canto responsorial, a rabeca e os metais acompanhados pela batida eletrônica que simula a percussão do maracatu rural. Tal assemblage sonora coloca em jogo significados de um possível maracatu eletrônico e reivindica presenças mais diversas nas mídias, ao inserir vozes que geralmente estão ausentes das configurações dos gêneros da indústria fonográfica, centralizados nos estilos musicais oferecidos no Ocidente como padrão de consumo na nova ordem global. A diversidade dos álbuns analisados neste texto, entretanto, não coloca o local em oposição ao globalizado, mas sugere uma alteridade radical, convivência rica e, ao mesmo tempo, fricativa que se estabelece na produção de diferença e no afastamento dos regimes que limitam campos estéticos.

Em reflexão sobre regimes de signos, Deleuze e Guattari (1995) identificam a existência de outra configuração semiótica capaz de romper com padronizações semânticas. Os filósofos usam o exemplo dos povos nômades e seu constante estado migratório como um problema para a burocracia estatal em que a pluralidade móvel configuraria uma máquina de guerra contra o aparelho de Estado (1995, p. 58). Da mesma forma e de fato, a força tradutória da movência estética se mostra problemática sempre que se coloca frente a situações de enquadramentos muito delimitados. Pensando na forma discursiva dos gêneros fonográficos, não há limites para categorizar o álbum Frevotron que, além de colocar diversas vertentes sonoras, instrumentações e seus respectivos índices culturais de origem em contato, reúne participações como a da francesa Marion Lemonnier e Jorge Du Peixe (Nação Zumbi), nas faixas Soufle et son e Travessia, respectivamente. Ambos ethos distintos que enunciam subjetividades marcadoras de significados, atuando no campo das percepções, pois vozes são também materialidades

\footnotetext{
"Retirado de https://www.youtube.com/watch?v=A1_ss9cjdGs
} 
que, em suas respectivas aparições, comunicam algo: o ato de colocar a voz em ação está contextualizado em territorialidades e seus agenciamentos, o cantar em Francês e o vocalista pernambucano.

Historicamente, criou-se um campo delimitado que valoriza estilos musicais ocidentais. Esse padrão impõe-se nas práticas de circulação e consumo, e opera em especial nas narrativas que compõem a memória da música pop. Os discos Contraditório? e Frevotron sugerem variações semânticas, pois são compostos por diferentes textos culturais cuja leitura demanda alteridade, até porque o "sujeito se forma e se transforma no discurso que comunica ao outro" (Kristeva, 1988, 12). A escolha de cada elemento sonoro (timbres, ritmo) e material (instrumentos), portanto, está relacionado a uma afirmação de transformação.

Inerente à mudança é a ideia de revisar a memória para valorizar subjetividades excluídas pelo esquecimento, no que diz respeito às narrativas da música pop nas mídias. Esse movimento soa como ecos de vozes emudecidas, como pontuou Walter Benjamin (1987, p. 223), ao defender em suas teses sobre história um olhar redentor e revisionista em relação ao passado. Sugerimos, dessa forma, que a produção de diferença e seus desdobramentos comunicacionais, na música pop, desempenha esse papel de colocar narrativas subterrâneas à mostra na memória para enfrentar regimes que atuam sobre a produção de linguagem musical (Carvalho, 2017; Pollak, 1989). O artista experimental, a exemplo do DJ Dolores, se coloca no campo de tais mudanças ao propor novas narrativas no cenário da música pop.

\section{CONSIDERAÇÕES FINAIS}

A audição atenta dos dois discos do DJ Dolores, como proposto neste artigo, nos traz algumas conclusões. Em primeiro lugar, as peças experimentais do disc-jóquei, ao articularem elementos de gêneros musicais distintos, acionam novas posturas de audição, para que os ouvintes tenham a possibilidade de rearticular os sentidos colocados em pauta pelos hibridismos. Pede-se aqui um ouvinte atento que observe esses dados, que seja capaz de captar, tal qual um arqueólogo, seus regimes de sentido, e que reconstrua a narrativa musical e seus elementos significantes no todo da canção.

Em segundo, o experimentalismo de Dolores redefine a própria noção de música eletrônica e sua compartimentação de acordo com seus beats específicos. Aqui, o trânsito e as traduções de gêneros colocam as peças musicais em constante estado nômade, escorregando de gênero em gênero, instrumento em instrumento, timbre em timbre. Um regime móvel de indefinição, pleno em filtros tradutores, é o que melhor caracteriza essa manifestação cultural.

Por fim, traz uma proposta radical de questionamento das instâncias definidoras da indústria fonográfica pautadas em regimes semânticos reconhecíveis e de mais fácil assimilação. Ao contrário, a música de Dolores sugere uma abertura radical nas formas de definição das obras musicais. Ou, mais além das estratificações, indica um caminho para uma música verdadeiramente universal, passível de ser fruída por todos por não conter apenas os elementos facilmente reconhecíveis. 


\section{REFERÊNCIAS BIBLIOGRÁFICAS}

Ades, D. (1994). Dadá e surrealismo. In N. Stangos (Ed.), Conceitos da arte moderna (pp. 81-99). Rio de Janeiro: Jorge Zahar Ed.

Baudrillard, J. (1991). La transparencia del mal. Ensayo sobre los fenómenos extremos. Barcelona: Editorial Anagrama.

Baugh, B. (1994). Prolegômenos a uma estética do rock. Novos Estudos, 38, 15-23.

Benjamin, W. (1987). Magia e técnica, arte e política - Obras escolhidas, v. 1. São Paulo: Brasiliense.

Carvalho, N. F. (2017). Música no exílio: a linguagem musical do grupo songhoy blues como alteridade na memória da música pop nas mídias. XXXX Congresso Brasileiro de Ciências da Comunicação - Intercom. Curitiba. Retirado de http://portalintercom.org.br/anais/nacional2017/resumos/R12-0464-1.pdf

Conter, M. B. \& Silveira, F. L. (2014). Sampleamento de imagens sonoras em Fear of a Black Planet. Resonancias, 19(35), 47-60. doi: 10.7764/res.2014.35.4

Deleuze, G. \& Guattari, F. (1995). Mil platôs - capitalismo e esquizofrenia, v. 2. São Paulo: Editora 34.

Derrida, J. (1991). Margens da filosofia. São Paulo: Papirus.

Fabbri, F. (1982). A theory of musical genres: two applications. In D. Horn \& P. Tagg (Eds.), Popular music perspectives (pp. 52-81). Göteborg \& Exeter: IASPM.

Felinto, E. (2001). Materialidades da comunicação: por um novo lugar da matéria na teoria da comunicação. Ciberlegenda, 5, 1-16. Retirado de http://www.ciberlegenda.uff.br/index.php/revista/article/view/308

Ferreira, A. \& Rabot, J-M. (2017). Música eletrónica de dança: ambiguidades discursivas. Revista Lusófona de Estudos Culturais/Lusophone Journal of Cultural Studies, 4(2), 297-311. Retirado de http://rlec.pt/index. $\mathrm{php/rlec/article/view/257/190}$

Hall, S. (2003). Da diáspora: identidades e mediações culturais. Belo Horizonte: UFMG.

Haraway, D. J. (2000). Manifesto ciborgue: ciência, tecnologia e feminismo-socialista no final do século XX. In T. Tadeu (Ed.), Antropologia do ciborgue. As vertigens do pós-humano (pp. 33-118). Belo Horizonte: Autêntica.

Kellner, D. (2001). A cultura da mídia. Bauru: Edusc.

Kristeva, J. (1988). El lenguaje, ese desconocido. Introducción a la lingüística. Madrid: Editorial Fundamentos.

Lotman, I. (1998). La semiosfera II. Semiótica de la cultura, del texto, de la conducta y del espacio. Madrid: Ediciones Cátedra.

Pollak, M. (1989). Memória, esquecimento, silêncio. Estudos Históricos, 2(3), 3-15. Retirado de http://www.uel. $\mathrm{br} / \mathrm{cch} / \mathrm{cdph} /$ arqtxt/Memoria_esquecimento_silencio.pdf

Reynolds, S. (2011). Retromania: pop culture's addiction to its own past. Londres: Faber and Faber.

Ribeiro, R. (2010). Pensar a identidade atonal da modernidade: breve fantasia a quatro mãos. Comunicação $e$ Sociedade, 18, 193-200. doi: 10.17231/comsoc.18(2010).998

Trotta, F. (2008). Gêneros musicais e sonoridade: construindo uma ferramenta de análise. Ícone, 10(2), 1-12.

Vargas, H. (2007). Hibridismos musicais de Chico Science a Nação Zumbi. Cotia: Ateliê Editorial. 
Zielinski, S. (2005). A arqueologia da mídia. In L. Leão (Ed.), O chip e o caleidoscópio: reflexões sobre as novas mídias (pp. 53-71). São Paulo: SENAC.

\section{NOTAS BIOGRÁFICAS}

Herom Vargas é doutorado em Comunicação e Semiótica e professor do Programa de Pós-Graduação em Comunicação da Universidade Metodista de São Paulo. É doutorado em Comunicação e Semiótica pela Pontifícia Universidade Católica de São Paulo (PUC-SP).

Foi vice-presidente do Latin American Branch da International Association for the Study of Popular Music (IASPM) entre 2014 e 2016. É autor do livro Hibridismos musicais de Chico Science a Nação Zumbi (São Paulo, 2007) e editor, com Tanius Karam, da obra De norte a sur: música popular y ciudades en América Latina. Apropiaciones, subjetividades $y$ reconfiguraciones (Merida-México, 2015).

E-mail: heromvargas50@gmail.com

Morada: UMESP, Rua Grito, 525 / 142, Ipiranga, CEP 04217-000, São Paulo / SP (Brasil).

Nilton Carvalho é estudante de Doutorado do Programa de Pós-Graduação em Comunicação da Universidade Metodista de São Paulo. Os seus interesses de investigação concernem o experimentalismo e os hibridismos na música pop e as experiências de Comunicação do outro nas canções que escapam aos géneros fonográficos estandardizados. A sua pesquisa baseia-se na Semiótica da Cultura, materialidades, micropolítica, identidade e memória. É jornalista e trabalha sobre Direitos Humanos e imigração.

E-mail: niltonblog@gmail.com

Morada: Rua Urupema Street, 263, Oswaldo Cruz, CEP 09540-310, São Caetano do Sul / SP (Brasil)

* Submetido: 30-11-2017

* Aceite: 15-02-2018 